\title{
Covid-19: Procedimentos Minimamente Invasivos em Odontopediatria
} Covid-19: Minimally Invasive Procedures In Pediatric Dentistry

\author{
Laura Marcelly Teixeira Gomes ${ }^{1}$ \\ Alice Duarte Santos Veloso ${ }^{2}$ \\ Antônio Cavalcanti Oliveira Filho ${ }^{3}$ \\ Ítalo Filipe França ${ }^{4}$ \\ Maria Fernanda Souza Ramos 5 \\ Maria José Lages de Oliveira ${ }^{6}$ \\ Verônica Oliveira Dias ${ }^{7}$
}

Resumo: Em meio à pandemia da doença Coronavírus (COVID-19), a prática odontopediátrica passa por novo cenário, considerando que crianças podem ser portadoras assintomáticas do vírus e o ambiente odontológico considerado um local de risco. Procedimentos odontológicos envolvem exposição à saliva e à secreções nasofaríngeas, bem como produção de aerossóis e gotículas, fontes de transmissão. Além dos cuidados de biossegurança comuns nos consultórios e đos recomendados pela Organização Mundial da Saúde contra o Coronavírus, procedimentos odontológicos minimamente invasivos, visando reduzir ou eliminar a produção dos aerossóis, adquirem, neste momento, grande importância. Objetivo: Apresentar revisão bibliográfica narrativa sobre procedimentos minimamente invasivos utilizados na Odontopediatria diante da pandemia da COVID-19. Método: Foi

\footnotetext{
${ }^{1}$ Acadêmica em Odontologia, Universidade Estadual de Montes Claros (Unimontes). Minas Gerais. Brasil. $\square$ laura.marcelly98@gmail.com. (D) https://orcid.org/0000-0001-8968-0636.

${ }^{2}$ Acadêmica em Odontologia, Universidade Estadual de Montes Claros (Unimontes). Minas Gerais. Brasil. $\square$ liceduartesv@gmail.com. (D) https://orcid.org/0000-0003-1309-2592.

${ }^{3}$ Acadêmico em Odontologia, Universidade Estadual de Montes Claros (Unimontes) Minas Gerais. Brasil. $\square$ tomcavalcanti@icloud.com. (D) https://orcid.org/0000-0002-5087-9119.

4 Acadêmica, Universidade Estadual de Montes Claros (Unimontes). Minas Gerais. Brasil. $\square$ italoff22@gmail.com. (D) https://orcid.org/0000-0002-6424-9214.

${ }^{5}$ Acadêmica em Odontologia, Universidade Estadual de Montes Claros (Unimontes) Minas Gerais. Brasil. $\square$ nandasra18@gmail.com. (D) https://orcid.org/0000-0002-7749-565X.

${ }^{6}$ Doutora em Odontopediatria (UFMG). Professora da Universidade Estadual de Montes Claros (Unimontes). Minas Gerais. Brasil. $₫$ lagesdeoliveira@gmail.com. (iD https://orcid.org/0000-0003-0146-6059.

${ }^{7}$ Doutora em Ciências da Saúde (Unimontes). Professora da Universidade Estadual de Montes Claros (UNIMONTES). Minas Gerais. Brasil. $₫$ veronicaunimontes@yahoo.com.br. (D) https://orcid.org/00000003-1989-7797.

$\begin{array}{cccc}\text { Recebido em } & \text { Correções em } & \text { Aceito em } & \text { Publicado em } \\ 31 / 07 / 2020 & 01 / 11 / 2000 & 15 / 12 / 2020 & 31 / 12 / 2020\end{array}$
}


realizada uma revisão da literatura utilizando a base de dados da Biblioteca Virtual em Saúde, dos últimos 10 anos, empregando os descritores: "Coronavirus", "COVID-19", "Children", "Pediatric Dentistry", "Conservative treatment". Resultados: A literatura possui diversas opções de procedimentos minimamente invasivos que podem ser usados em Odontopediatria diante da pandemia pela COVID-19. Conclusões: As técnicas minimamente invasivas são procedimentos que, no contexto da pandemia de COVID-19, evitam ou eliminam a produção de aerossóis, apresentam abordagem conservadora, biológica, com boa relação custo/benefício, acessível aos serviços públicos de saúde e com eficiência no controle da doença cárie dentária.

Palavras-chave: Coronavírus; COVID-19; Crianças; Odontopediatria; Tratamento Conservador.

Abstract: In the midst of the Coronavirus disease pandemic (COVID-19), a pediatric practice undergoes a new scenario, considering that these children may be asymptomatic carriers of the virus and the dental environment considering a risky place. Dental procedures involve exposure to saliva and nasopharyngeal secretions, as well as the production of aerosols and droplets, sources of transmission. In addition to the common biosafety precautions in offices and those recommended by the World Health Organization against or Coronavirus, minimally invasive dental procedures, reducing or eliminating the production of aerosols, acquire, in this importance, great importance. Objective: presentation of a narrative bibliographic review on minimally invasive procedures used in the Pediatric Dentistry of the pandemic COVID-19. Method: A literature review was carried out using the Virtual Health Library database of the last 10 years, using the descriptors: "Coronavirus", "COVID-19", "Children", "Pediatric Dentistry", "Conservative treatment". Results: The literature has several options for minimally invasive procedures that can be used in pandemic pediatric dentistry by COVID-19. Conclusions: Minimally invasive techniques are procedures that, in the context of the COVID-19 pandemic, prevent or eliminate the production of aerosols, present a conservative, biological approach, with a good cost/benefit ratio, accessible to your dental caries disease control services.

Keywords: Coronavirus; COVID-19; Children; Pediatric Dentistry; Conservative treatment.

\section{INTRODUÇÃO}

Em dezembro de 2019, um surto de pneumonia iniciou na China e se espalhou por várias regiões geográficas, causado pelo vírus denominado de novo Coronavírus (2019nCoV) ${ }^{1}$. Após o crescente número de casos, em março de 2020, a Organização Mundial da Saúde/OMS ${ }^{2}$ declarou que a doença causada pelo novo Coronavírus (Coronavírus disease ou COVID-19) é caracterizada como uma pandemia ${ }^{2,3}$. 
A COVID-19 é transmitida por meio da saliva e de secreções da nasofaringe de pessoas infectadas e as vias de transmissão do vírus são por contato direto com superfícies contaminadas ou através de aerossóis ${ }^{4,5}$.

Embora seja relatado que o número de casos em crianças é baixo em comparação com os adultos, estas também são propensas à infecção pela COVID-196. Considerando o longo período de incubação da doença (até 14 dias) ${ }^{7}$ e avaliando que as crianças podem ser assintomáticas ou apresentarem sintomas leves e inespecíficos, todas as crianças e seus responsáveis devem ser considerados portadores potenciais da COVID-19 ${ }^{8,9}$.

Crianças podem apresentar alta carga viral para a doença, mesmo assintomáticas ou com manifestações amenas da COVID- $19^{10}$. Isso deixa os profissionais da Odontologia em situação potencial de alto risco ${ }^{9}$.

Como os procedimentos odontológicos; envolvem exposição à saliva e às secreções da nasofaringe, além da produção de aerossóis e gotículas, potenciais fontes de contaminação, existe um alto risco de transmissão de infecções respiratórias agudas ${ }^{11}$. Além dos cuidados de biossegurança, comuns nos consultórios odontológicos, e os recomendados pela Organização Mundial da Saúde contra o coronavírus, surge a necessidade de uma nova discussão sobre as medidas que podem ser adotadas pelos odontopediatras, a fim de minimizar o risco de contaminação cruzada na prática clínica durante a pandemia da COVID-19. Os procedimentos odontológicos que sejam minimamente invasivos, visando reduzir ou eliminar a produção dos aerossóis, são considerados uma opção de grande relevância no atual cenário ${ }^{12}$.

Baseado no exposto e diante da pandemia pela COVID-19, este trabalho tem como propósito apresentar uma revisão da literatura de procedimentos minimamente invasivos utilizados na Odontopediatria.

\section{MÉTODO}

Foi realizada uma pesquisa bibliográfica narrativa nas bases de dados da Biblioteca Virtual em Saúde (BVS), que incorpora Literatura Latino-americana e do Caribe em Ciências da Saúde (Lilacs), Scientific Electronic Library Online (SciELO), Medical Literature Analysis and Retrieval System On-line (Medline), utilizando os descritores: “Coronavirus", “COVID-19”, "Children", "Pediatric Dentistry" e "Conservative treatment", dos últimos 10 anos (de 2010 a 2020), publicados em inglês, português e espanhol. 
A revisão foi norteada pela pergunta: "Quais são os procedimentos realizados na Odontopediatria que reduzem ou eliminam a produção dos aerossóis?’.

Foram encontrados 534 artigos relacionados com os temas "Pediatric Dentistry" e "Conservative treatment" e 13 artigos abordando "Pediatric Dentistry", "Coronavirus" e "COVID-19", resultando em um total de 52 artigos, os quais abordavam claramente o tema proposto.

\section{RESULTADOS E DISCUSSÃO}

\section{Atendimento odontopediátrico com técnicas mínimas de intervenção}

Diante da pandemia pela COVID-19, para evitar a disseminação do vírus e reduzir o risco de contaminação entre pacientes, profissionais e equipe, torna-se pertinente modificar os protocolos de atendimento odontopediátricos, que passam a priorizar a realização de procedimentos odontológicos minimamente invasivos, visando reduzir ou eliminar a produção dos aerossóis. Ademais, faz-se necessária a conscientização do paciente ou responsável a respeito da importância da prática da escovação com dentifrícios fluoretados, objetivando impedir o desenvolvimento de cárie dentaria ${ }^{9,13,14}$.

A Odontologia Minimamente Invasiva (OMI) consiste na abordagem de promoção de saúde e de preservação da saúde bucal, possibilitando o reparo da sequela da doença cárie (lesão) da forma menos invasiva possível, buscando manter ao máximo o tecido original do dente ${ }^{15,16}$.

A OMI apresenta abordagem conservadora e biológica, com eficiência no controle da doença cárie e não demanda o uso da alta rotação ou seringa tríplice, que são agentes geradores de bioaerossóis ${ }^{14}$.

Diversas são as técnicas minimamente invasivas que podem ser empregadas na Odontopediatria, sejam elas químicas ou mecânicas (Tabela 1).

É importante ressaltar que considerando o cenário atual da pandemia do Coronavírus, a Agência Nacional de Vigilância Sanitária (ANVISA) publicou notas técnicas para o atendimento odontológico. Essas notas técnicas estabelecem diversas regras para a assistência odontológica, dentre elas, o uso prioritário de dispositivos manuais ao atender, para evitar produção de aerossóis ${ }^{17}$. Sugere-se, portanto, que sempre que possível, sejam realizadas técnicas minimamente invasivas. 


\section{Remoção química e mecânica da lesão cariosa}

A remoção química e mecânica da cárie representa uma combinação de procedimentos que usam agentes químicos que proporcionam o amolecimento do tecido cariado da dentina e favorecem sua retirada com o uso de instrumentos não cortantes, já que esta se torna friável e pode ser facilmente removida através da curetagem, preservando ao máximo o tecido dentário sadio ${ }^{18}$. Nos anos 90 , um produto para a remoção química e mecânica da cárie foi desenvolvido, denominado Carisolv ${ }^{\circledR}$, composto por aminoácidos e hipoclorito de sódio ${ }^{19}$. Embora o Carisolv ${ }^{\circledR}$ se apresente eficaz, sua utilização no Brasil é restrita devido à necessidade de ser importado e ao seu elevado custo ${ }^{19}$.

Em 2003, uma formulação brasileira foi lançada no mercado. Denominada Papacárie ${ }^{\circledR}$, trata-se de um gel à base de papaína, cloramina, azul de toluidina, sais e espessante. Suas vantagens envolvem biocompatibilidade com os tecidos bucais, atoxicidade, efetividade, baixo custo e não demanda aparatos tecnológicos para seu uso ${ }^{20}$.

Quanto às vantagens em relação ao paciente, além de não possuir contraindicações, os benefícios dessa técnica englobam o fato de ser atraumática, poder ser aplicada em qualquer tipo de lesão cariosa em dentes decíduos e permanentes e não necessitar do uso de anestesia local, viabilizando a técnica para pacientes pediátricos ${ }^{21}$.

O emprego do Papacárie ${ }^{\circledR}$ também diminui o número de bactérias patogênicas, com consequente estabilização da cárie, devido à presença do azul de toluidina em sua composição, o qual atua como agente fotosenssibilizante. As vantagens desse tipo de terapia para o paciente estão relacionadas à promoção de uma destruição celular seletiva e da ausência de risco de acumular toxicidade, tornando o procedimento passível de repetição, caso necessário ${ }^{22,23}$. A desvantagem seria o tempo clínico, por vezes maior, em função da necessidade de reaplicação do produto em alguns $\operatorname{casos}^{24}$.

\section{Vernizes fluoretados}


Os vernizes fluoretados têm sido descritos como uma intervenção não invasiva para o tratamento de lesões de cárie, como forma mais conveniente para o uso profissional do flúor tópico e de possibilitar um contato mais duradouro dessa substância com a superfície dental. O objetivo desse produto é prevenir o surgimento de lesões cariosas, interromper as lesões já existentes e colaborar com a remineralização do dente ${ }^{25}$.

A aplicação tópica de vernizes fluoretados pode ser realizada a cada seis meses, uma vez que promove redução substancial no incremento da cárie, devendo ser realizada nas superfícies dentárias com maior potencial para desmineralização ${ }^{26}$.

As vantagens desse produto são a fácil aplicação, menor o risco de ingestão de flúor, boa tolerância pelas crianças e a capacidade de aderir às superfícies de esmalte, fazendo com que haja maior contato e consequente alta absorção de íons flúor ${ }^{14,27}$. A desvantagem seria a necessidade de limpeza prévia e secagem dos dentes para retenção do verniz $^{28}$.

\section{Diamino fluoreto de prata}

O Diamino Fluoreto de Prata (DFP) é uma solução com propriedades preventivas e cariostáticas, utilizada na prevenção de cárie em sulcos e fissuras. Apresenta em sua formulação o hidróxido de amônia, nitrato de prata, hidróxido de cálcio, ácido fluorídrico e solvente; o produto é comercializado nas concentrações de 10\%, 12\%, 30\% e $38 \%{ }^{29}$. Um ponto questionável é o escurecimento dos dentes, comprometendo estética ${ }^{30}$. Sua aplicação semestral é capaz de controlar a cárie, agindo como remineralizante no esmalte e na dentina. É indicado para pacientes com alto risco de cárie, podendo ser usado em qualquer dentição ${ }^{31,32}$.

O DFP apresenta baixo custo, facilidade de aplicação e é considerado um medicamento de ataque em situações de múltiplas lesões de cárie ativa associadas a hábitos inadequados de higiene e dieta. Sua aplicação em crianças é viável por ser um procedimento indolor e não invasivo. Há, ainda, a possibilidade de que esse material possa aumentar a remineralização da matriz colágena dentinária através da obliteração de seus túbulos, ampliando a densidade mineral da dentina enquanto reduz a profundidade da lesão cariosa $^{14,32,33}$.

\section{Selantes}


Os procedimentos odontológicos conservadores, como a aplicação de selantes, podem ser uma alternativa dentro da filosofia de mínima intervenção, visto que são materiais fluidos eficientes no controle e prevenção da cárie dentária, agindo por meio da formação de uma barreira física que impede o contato entre o dente e o biofilme, evitando procedimentos mais agressivos. São aplicados em áreas retentivas que possuem maior potencial em acumular resíduos provenientes da alimentação, como cicatrículas, fóssulas e fissuras ${ }^{34,35,36}$.

Diversos materiais vêm sendo propostos para o selamento de fóssulas e fissuras oclusais. Os selantes mais utilizados são os resinosos e ionoméricos. Os selantes resinosos possuem altas taxas de retenção, porém são clinicamente limitados pelas dificuldades quando não têm um adequado controle da umidade ${ }^{37}$. Os selantes ionoméricos apresentam menor retenção; por outro lado, são eficazes devido à capacidade de liberação de flúor e, consequentemente, apresentam maior efeito preventivo contra a cárie dentária ${ }^{36,38}$.

Os selantes podem ser usados de forma preventiva quando há elevado risco e/ou atividade de cárie e como agente terapêutico em pequenas lesões cavitadas em esmalte e dentina. São também indicados para dentes posteriores com morfologia oclusal altamente retentiva, com presença de fossas e fissuras ${ }^{14,39}$.

\section{Tratamento Restaurador Atraumático}

O Tratamento Restaurador Atraumático (ART) é uma proposta alternativa para o tratamento da cárie, que se iniciou objetivando não necessitar do auxílio de equipamentos rotatórios, podendo ser empregado fora do ambiente odontológico. Por ter comprovado se tratar de uma técnica efetiva no controle da doença cárie, o ART passou a ser usado também nos consultórios ${ }^{40,41}$.

O ART consiste na remoção seletiva do tecido cariado amolecido na dentina com instrumentos manuais, como colher/escavador de dentina (cureta), e selamento da cavidade com material restaurador adesivo, sendo usado o cimento de ionômero de vidro (CIV) de alta viscosidade. O CIV apresenta qualidades como a adesividade e presa químicas, biocompatibilidade, coeficiente de expansão térmico linear semelhante à estrutura dentária e liberação e incorporação de flúor, que previnem o surgimento de novas lesões cariosas e paralisam as já existentes ${ }^{42,43}$. 
Os benefícios dessa técnica envolvem a fácil realização, baixo custo, menor destruição do tecido dental, redução tempo clínico de atendimento e minimização do número de exposições pulpares, endodontias e exodontias, além de menor destruição do tecido dental. É um procedimento seguro e praticamente indolor feito, geralmente, sem aplicação de anestesia local, o que reduz a ansiedade do paciente infantil ${ }^{40,41,43}$.

A aplicação dessa técnica é restrita a dentes sem envolvimento pulpar, ou seja, sem presença de dor, abscesso, fístula ou mobilidade ${ }^{40,41,42}$.

\section{Técnica Hall}

A Técnica Hall é uma alternativa às técnicas restauradoras convencionais, indicada para molares decíduos com lesões cariosas envolvendo duas ou mais superfícies. Fundamenta-se na cimentação de coroas de aço inoxidável pré-fabricadas e pré-contornadas com uso de cimento ionômero de vidro em dentes não preparados, sem remoção de tecido cariado e sem aplicação de anestesia local. Esse procedimento proporciona um selamento ideal da lesão de cárie, com consequente inviabilização de seu desenvolvimento, uma vez que interrompe o contato com o biofilme cariogênico do meio bucal ${ }^{44,45,46,47}$.

O uso de coroas de aço nessa técnica está relacionado à alta longevidade quando comparada a qualquer outro procedimento restaurador e, por isso, geralmente irá acompanhar o dente decíduo até sua esfoliação. A Técnica Hall apresenta taxas de êxito equivalentes à de métodos que removam completamente as lesões de cáries, além de possuir sucesso do tratamento após cinco anos de acompanhamento superior aos 90\%, enquanto restaurações convencionais só atingem cerca de $40 \%^{14,44,46}$. A principal desvantagem que inviabiliza o uso corriqueiro dessa técnica é a dificuldade em encontrar as coroas de aço no mercado nacional. Além disso, o comprometimento estético, ponto de contato deficiente e falhas na intercuspidação devido à padronização da anatomia das coroas também são pontos negativos a serem considerados ${ }^{45,48}$.

\section{Aplicação de infiltrantes na superfície dental}

Recentemente, foi lançada no mercado internacional uma resina de baixa viscosidade, com alto poder de penetração e fotopolimerizável, conhecida como infiltrantes. Trata de um material que permite tratamento de lesões iniciais de cárie sem a necessidade 
de aberturas cavitárias ${ }^{49}$, além de fortalecer, estabilizar e preencher o esmalte desmineralizado, sem causar quaisquer preparos ou danos à estrutura do dente saudável ${ }^{50}$.

O infiltrante resinoso apresenta eficácia relevante na inibição do progresso da doença cárie em lesões iniciais de manchas brancas não cavitadas e lesões proximais em ambas as dentições, além de reduzir os efeitos de fluorose e a fragilidade dos dentes com defeitos de esmalte, tais como hipoplasia e amelogênese imperfeita ${ }^{50}$.

A resina infiltrante é uma técnica de rápida execução, mas apresenta a desvantagem de ser um material de alto custo. Outro ponto que vale ressaltar é a não resistência suficiente para evitar a recorrência de novas lesões cariosas, o que ocorre devido a alguns desses infiltrantes apresentarem componentes à base de trietilenoglicoldimetacrilato (TEGDMA), o qual apresenta alta hidrofilia e consequente degradação no meio oral ${ }^{50,51}$.

Tabela 1: Procedimentos minimamente invasivos aplicados em Odontopediatria e suas características.

\begin{tabular}{|c|c|c|c|}
\hline Técnica & Indicações & Vantagens & Desvantagens \\
\hline $\begin{array}{l}\text { Remoção } \\
\text { química e } \\
\text { mecânica da } \\
\text { lesão } \\
\text { cariosa }\end{array}$ & $\begin{array}{l}\text { Lesões cariosas } \\
\text { em dentes } \\
\text { decíduos e } \\
\text { permanentes }\end{array}$ & $\begin{array}{l}\text { Reduz uso de instrumentos } \\
\text { rotatórios, não usa anestesia } \\
\text { local, boa aceitação, pode } \\
\text { ser usada com isolamento } \\
\text { relativo e baixo custo }\end{array}$ & $\begin{array}{l}\text { Aumento do tempo de } \\
\text { execução de clínica }\end{array}$ \\
\hline $\begin{array}{l}\text { Vernizes } \\
\text { fluoretados }\end{array}$ & $\begin{array}{l}\text { Prevenir novas } \\
\text { lesões cariosas, } \\
\text { paralisar lesões } \\
\text { existentes e } \\
\text { remineralização }\end{array}$ & $\begin{array}{l}\text { Fácil aplicação, menor o } \\
\text { risco de ingestão de flúor, } \\
\text { maior capacidade de aderir } \\
\text { às superfícies de esmalte e } \\
\text { alta ação remineralizadora }\end{array}$ & $\begin{array}{l}\text { Necessidade de } \\
\text { limpeza prévia e } \\
\text { secagem dos dentes } \\
\text { para retenção do } \\
\text { verniz }\end{array}$ \\
\hline $\begin{array}{l}\text { Diamino } \\
\text { fluoreto de } \\
\text { prata }\end{array}$ & $\begin{array}{l}\text { Alto risco de } \\
\text { cárie, dentes } \\
\text { decíduos e } \\
\text { permanentes }\end{array}$ & $\begin{array}{l}\text { Baixo custo, fácil aplicação } \\
\text { e indolor }\end{array}$ & $\begin{array}{l}\text { Escurecimento dos } \\
\text { dentes com } \\
\text { comprometimento } \\
\text { estético }\end{array}$ \\
\hline Selantes & $\begin{array}{l}\text { Elevado risco } \\
\text { e/ou atividade de } \\
\text { cárie, pequenas } \\
\text { lesões cavitadas, } \\
\text { dentes com } \\
\text { oclusal retentiva }\end{array}$ & $\begin{array}{l}\text { Selantes resinosos: altas } \\
\text { taxas de retenção } \\
\text { Selantes ionoméricos: maior } \\
\text { liberação de flúor e maior } \\
\text { efeito preventivo }\end{array}$ & $\begin{array}{l}\text { Selantes resinosos: } \\
\text { necessitam de maior } \\
\text { controle da umidade } \\
\text { Selantes ionoméricos: } \\
\text { menor retenção }\end{array}$ \\
\hline
\end{tabular}




\begin{tabular}{llll}
$\begin{array}{l}\text { Tratamento } \\
\text { Restaurador } \\
\text { Atraumático }\end{array}$ & $\begin{array}{l}\text { Lesões cariosas } \\
\text { em dentina }\end{array}$ & $\begin{array}{l}\text { Baixo custo, menor } \\
\text { destruição dental, minimiza } \\
\text { exposições pulpares, } \\
\text { endodontias e exodontias, } \\
\text { não usa anestesia local }\end{array}$ & $\begin{array}{l}\text { Restrito a dentes sem } \\
\text { envolvimento pulpar, } \\
\text { (sem presença de dor, } \\
\text { abscesso, fístula ou } \\
\text { mobilidade) }\end{array}$ \\
\hline $\begin{array}{l}\text { Técnica } \\
\text { Hall }\end{array}$ & $\begin{array}{l}\text { Molares } \\
\text { decíduos com } \\
\text { lesões em duas } \\
\text { ou mais } \\
\text { superfícies }\end{array}$ & $\begin{array}{l}\text { Inviabiliza o } \\
\text { desenvolvimento da cárie, } \\
\text { não demanda preparo e nem } \\
\text { uso de anestesia local, } \\
\text { apresenta alta longevidade }\end{array}$ & $\begin{array}{l}\text { Difícil acesso no } \\
\text { mercado brasileiro, } \\
\text { comprometimento } \\
\text { estético e falhas nos } \\
\text { pontos de contato e } \\
\text { intercuspidação }\end{array}$ \\
\hline $\begin{array}{l}\text { Aplicação } \\
\text { de }\end{array}$ & $\begin{array}{l}\text { Lesões iniciais } \\
\text { infiltrantes manchas } \\
\text { brancas não } \\
\text { cavitadas, em } \\
\text { decíduos e } \\
\text { permanentes }\end{array}$ & $\begin{array}{l}\text { Fortalece e preenche o } \\
\text { esmalte desmineralizado } \\
\text { sem preparo, reduz os } \\
\text { efeitos de fluorose e a } \\
\text { fragilidade dos dentes com } \\
\text { defeitos de esmalte }\end{array}$ & $\begin{array}{l}\text { Material de alto custo } \\
\text { e não possui } \\
\text { resistência suficiente } \\
\text { para evitar a } \\
\text { recorrência de novas } \\
\text { lesões cariosas }\end{array}$ \\
\hline
\end{tabular}

As terapêuticas indicadas para o tratamento e prevenção da cárie dentária que minimizam ou eliminam a produção de aerossóis mostram a sua eficácia, podendo ser utilizadas no serviço público, juntamente com programas preventivos e de educação em saúde bucal ${ }^{52}$.

\section{CONCLUSÕES}

A atual pandemia de COVID-19 demanda novas condutas clínicas, especialmente na Odontopediatria, visto que as crianças podem ser assintomáticas para tal doença, consequentemente devendo ser tratadas como portadoras potenciais do vírus.

Esta revisão demostrou que as técnicas minimamente invasivas são procedimentos que, no contexto da pandemia de COVID-19, evitam ou eliminam a produção de aerossóis, apresentam abordagem conservadora e biológica, com boa relação custo/benefício, acessível aos serviços públicos de saúde e com eficiência no controle da doença cárie dentária.

\section{REFERÊNCIAS}


1 PENG, X. et al. Transmission routes of $\mathrm{n} 2019-\mathrm{nCoV}$ and controls in dental practice.

Int J Oral Sci., [S.1.], v.12, n.1, p.9, 2020.

2 WORLD HEALTH ORGANIZATION. WHO Director-General's opening remarks at the media briefing on COVID-19 - 11 March 2020. OMS, 2020. Disponível em: $<$ https://www.who.int/dg/speeches/detail/who-director-general-s-opening-remarks-atthe-media-briefing-on-covid-19---11-march-2020>. Acesso em: 24, jun, 2020.

3 GUO, YR. et al. The origin, transmission and clinical therapies on coronavirus disease 2019 (COVID-19) outbreak - an update on the status. Mil. Med. Res., [S.1.], v.7, n.11, p.11, 2020.

4 ATHER, A. et al. Coronavirus Disease 19 (COVID-19): Implications for Clinical Dental Care. Journal of endodontics, [S.1.], v.46, n.5, p.584-595, 2020.

5 GE, Z. Y. et al. Possible aerosol transmission of COVID-19 and special precautions in dentistry. J Zhejiang Univ Sci B., [S.1.], v.21, n.5, p.361-368, 2020.

6 HENRY, B. M.; OLIVEIRA, M. H. S. Preliminary epidemiological analysis on children and adolescents with novel coronavirus disease 2019 outside Hubei Province, China: an observational study utilizing crowdsourced data. medRxiv. 2020. (in press). doi:2020.03.01.20029884.

7 HUANG, C. et al. Clinical features of patients infected with 2019 novel coronavirus in Wuhan, China. The Lancet, [S.1.], v.395, n.10223, p.497-506, 2020.

8 LU, X. et al. SARS-CoV-2 infection in children. The New England Journal of Medicine, [S.1.], v.382, n.17, p.1663-1665, 2020.

9 MALLINENI, S.K. et al. Coronavirus disease (COVID-19): Characteristics in children and considerations for dentists providing their care. Int. J. Paediatr. Dent, [S.1.], v.30, n.3, p.245-250, 2020.

10 KAM, K-Q. et al. A Well Infant With Coronavirus Disease 2019 With High Viral Load. Clinical Infectious Diseases, [S.1.], ciaa201, 2020. (2020). doi: 10.1093/cid/ciaa201.

11 TRAN, K. et al. Aerosol generating procedures and risk of transmission of acute respiratory infections to healthcare workers: a systematic review. PLoS One, [S.1.], v.7, n.4, e35797, 2012. doi:10.1371/journal.pone.0035797

12 MENG, L.; HUA, F.; BIAN, Z. Coronavirus Disease 2019 (COVID-19): Emerging and future challenges for dental and oral medicine. J Dent Res., [S.1.], v.99, n.5, p.481-487, 2020.

13 CASAMASSIMO, P. S.; TOWNSEND, J. A.; LITCH, C. S. Pediatric Dentistry During and After COVID-19. Pediatr Dent, [S.1.], v.42, n.2, p.87-90, 2020.

14 ASOCIACIÓN LATINOAMERICANA DE ODONTOPEDIATRÍA. Tratamiento de caries en época de COVID-19: Protocolos clínicos para el control de generación de aerosoles. Revista de Odontopediatría Latinoamericana, [S.1.], v.10, n.2, 2020. 45p.

15 BUSSADORI, S. K. et al. Odontologia de Mínima Intervenção: um novo olhar sobre a Odontologia. Cartilha ART Nova DFL, jan. 2013. Disponível em:

<http://www.agoped.org.br/CartilhadeMinimaIntervencao.pdf $>$. Acesso em: 15 jun. 2020. 
16 PORTELA, A. S. et al. Odontologia minimamente invasiva: atividade e risco de cárie. 2018. 11f. Trabalho de Graduação (Graduação em Odontologia) - Universidade Vale do Rio Doce, UNIVALE, Governador Valadares, 2018.

17 AGÊNCIA NACIONAL DE VIGILÂNCIA SANITÁRIA. Nota Técnica GVIMS/GGTES/ANVISA No 04/2020. Orientações para serviços de saúde: medidas de prevenção e controle que devem ser adotadas durante a assistência aos casos suspeitos ou confirmados de infecção pelo novo coronavírus (SARS-CoV-2). Brasília: ANVISA, 27/out/2020, 104p. Disponível em: <https://www.saude.sc.gov.br/coronavirus/arquivos/NOTA_TECNICA_GVIMS_GG TES_ANVISA_04_2020_Reviso_27.10.2020.pdf>. Acesso em: 12, jan, 2021.

18 BUSSADORI, S. K; MOTTA, L. J.; PINTO, M. M. Manual de protocolos clínicos empregados em Odontopediatria. São Paulo: Universidade Nove de Julho UNINOVE, 2017. 202p.

19 LOPES, M. C.; MASCARINI, R. C.; BATING, R. T. Métodos químico-mecânicos para a remoção do tecido cariado. Arq. Odontol., Belo Horizonte, v.48, n.1, p. 53-58, 2012.

20 BOTTEGA, F. et al. Costs and benefits of Papacarie in pediatric dentistry: a randomized clinical trial. Sci Rep., [S.1.], v.8, n.17908, p.1-7, 2018.

21 DUCA, A. C. L. D. et al. Aplicabilidade clínica do gel à base de papaína em lesões cariosas agudas. JRD, [S.1], v.6, n.5, p.104-108, 2018.

22 MOTA, A. C. C. et al. Case Report of Photodynamic Therapy in the Treatment of Dental Caries on Primary Teeth. Journal of Lasers in Medical Sciences, [S.1.], v.7, n.2, p.131-133, 2016.

23 OLIVEIRA, I. B. et al. Avaliação "in vitro" do efeito antimicrobiano de diferentes concentrações de gel de papaína. Revista Conversas Interdisciplinares, [S.1.], v.13, n.3, 2017.

24 FREITAS, M. P. G. et al. Remoção químico-mecânica de lesão cariosa - uma revisão integrativa da literatura. Rev. Bras. Odonto., [S.1.], v.75, n.47, 2018.

25 CARVALHO, D. M. et al. O uso de vernizes fluoretados e a redução da incidência de cárie dentária em pré-escolares: uma revisão sistemática. Rev. Bras. Epidemiol., São Paulo, v.13, n.1, p.139-149, 2010.

26 RODRIGUES, L. P. et al. Revisão de literatura: Odontologia preventiva em pacientes ortodônticos - como prevenir e tratar as lesões de mancha branca? J. Multidiscipl. Dent., [S.1.], v.10, n.1, p.52-58, 2020.

27 SOARES, A. L. Efeito da aplicação de vernizes fluoretados com diferentes formulações nas lesões iniciais de cárie artificiais em dentes decíduos. 2016. 52f. Dissertação (Mestrado em Odontopediatria) - Faculdade de Odontologia de Piracicaba da Universidade Estadual de Campinas, UNICAMP, Piracicaba, 2016.

28 MILANEZ, G. B. Avaliação do conhecimento dos graduandos em odontologia da Universidade Federal de Santa Catarina em relação ao uso e prescrição de produtos fluoretados. 2014. 64f. Trabalho de Graduação (Graduação em Odontologia) - Universidade Federal de Santa Catarina, UFSC, Florianópolis, 2014. 
29 JUNIOR, V.E.S.; SOUZA, P.R.; ROSENBLATT, A. Um recurso para paralisar e prevenir cárie em crianças: Diamino fluoreto de prata. RFO, [S.1.], v.17, n.2, p.228233, 2012.

30 CRYSTAL, Y.O.; NIEDERMAN, R. Silver Diamine Fluoride Treatment Considerations in Children's Caries Management. Pediatr Dent., [S.1.], v.38, n.7, p.466-471, 2016.

31 GAO, S. S. et al. Clinical trials of silver diamine fluoride in arresting caries among children: a systematic review. JDR Clin Trans Res, [S.1.], v.1, n.3, p.201-210, 2016.

32 FAVARO, J. C.; BERGER, S. B. Diamino fluoreto de prata: revisão de literatura. In: $10^{\circ}$ Seminário de Iniciação Científica e $1^{\circ}$ Seminário de Pesquisa e Pós-Graduação Stricto Sensu - Kroton, 2019, Londrina, PR. Anais (on-line). Disponível: $<$ https://repositorio.pgsskroton.com//handle/123456789/24410>. Acesso em 23/06/2020.

33 RAMOS, C. D. et al. Uso de diamino fluoreto de prata em crianças atendidas em uma unidade básica de saúde do Norte do Paraná. R. Saúde Públ., [S.1.], v.1, n.1, p.68-73, 2018.

34 RICCI-DONATO, H. A. et al. SELANTES RESINOSOS: REVISÃO DE LITERATURA. Journal of Research in Dentistry, [S.1.], v.6, n.1, p.23-28, 2018.

35 MONÇÃO, L de S.; ONODERA, P. A. K. Selante resinoso de fóssulas e fissuras: relato de caso. 2018. 26f. Trabalho de Graduação (Graduação em Odontologia) UNIVERSIDADE DE UBERABA, UNIUBE, Uberaba, 2018.

36 LUZIA, T. L. de O.; SILVEIRA, A. D. S. Uso terapêutico dos selantes odontológicos. Revista Digital da Academia Paraense de Odontologia, Belém-PA, v.1, n.1, p.4146, 2017.

37 BHAT, P. K.; KONDE, S.; RAJ, S. N.; KUMAR, N. C. Moisture-tolerant resin-based sealant: A boon. Contemp Clin Dent, [S.1.], v.4, n.3, p.343-348, 2013.

38 SEIXAS, G. F. Uso de selantes resinosos e ionoméricos em dentição decídua. 2017. 46f. Tese (Doutorado em Odontologia) - Universidade Pitágoras Unopar, UNOPAR, Londrina, 2017.

39 NUNES FILHO, G. de F. Revisão Narrativa Sobre o Uso e Técnicas dos Selantes de Fissuras. 2019. 27f. Relatório de estágio (Mestrado Integrado em Medicina Dentária) - Instituto Universitário de Ciências da Saúde, IUCS, Gandra, 2019.

40 ASAKAWA, L.; FRANZIN, L. C. da S.. Tratamento restaurador atraumático (ART): uma visão contemporânea. Revista Uningá Review, [S.1.], v. 29, n. 1, 2017.

41 SILVA, A. de A. O tratamento restaurador atraumático diante da cárie dentária: uma revisão de literatura. 2019. 29f. Trabalho de Graduação (Graduação em Odontologia) - Universidade Federal do Rio Grande do Norte, UFRN, Natal, 2019.

42 NAVARRO, M. F. L. et al. Tratamento Restaurador Atraumático: atualidades e perspectivas. Rev Assoc Paul Cir Dent, [S.1.], v.69, n.3, p.289-301, 2015.

43 SANTANA, V. K. R.; PEREIRA, E. F.; BOTELHO, K. V. G. Tratamento restaurador atraumático - TRA, o que é, indicações, contra indicações, protocolo clínico do TRA, e como implantar esta técnica na rotina do cirurgião dentista. Caderno de Graduação - Ciências Biológicas e de Saúde Unit, Recife, v.3, n.3, p.33-42, 2018. 
44 ALTOUKHI, D. H.; EL-HOUSSEINY, A. A. Hall Technique for Carious Primary Molars: A Review of the Literature. Dent. J., [S.1.], v.8, n.11, 2020.

45 GROSS, D. J. et al. Hall technique in pediatric patients: case study and clinicalradiographic follow-up. Brazilian Journal of Dentistry, São Paulo, v.75, 2018.

46 CLARK, W. et al. Success rates of Hall technique crowns in primary molars: a retrospective pilot study. Gen Dent., [S.1.], v.65, n.5, p.32-35, 2017.

47 ROBERTS, A.; MCKAY, A.; ALBADRI, S. The use of Hall technique preformed metal crowns by specialist paediatric dentists in the UK. British Dental Journal, [S.1.], v.224, n.1, p.48-52, 2018.

48 ZANOLA, M. M. O. et al. Hall Technique: você sabe o que é? Relato de caso. Rev. Assoc. Paul. Cir. Dent., [S.1.], v.72, n.4, p.624-630, 2018.

49 RIBEIRO, L. S. M. V.; OLIVEIRA, C. T. P.; ARAÚJO, L. S. N. Infiltrantes e suas aplicações. Revista Interfaces: Saúde, Humanas e Tecnologia, [S.1.], v.3, n.9, p.7580, 2016.

50 SANT'ANNA, G. R. et al. Infiltrante resinoso vs Microabrasão no manejo de lesões de mancha branca: relato de caso. Rev. Assoc. Paul. Cir. Dent., São Paulo, v.70, n.2, 2016.

51 FREITAS, M. C. C. de A. Efeito de um infiltrante resinoso no tratamento de lesões de mancha branca: análise in vitro e in situ. 2015. 154f. Tese (Doutorado em Dentística) - Faculdade de Odontologia de Bauru, University of São Paulo, Bauru, 2015.

52 KUHNEN, M.; BURATTO, G.; SILVA, M. P. Uso do tratamento restaurador atraumático na Estratégia Saúde da Família. Rev. Odontol. UNESP, [S.1.], v.42, n.4, p.291-297, jul-ago 2013. 